\title{
Improved Chemical Amplification Instrument by Using a Nafion Dryer as an Amplification Reactor for Quantifying Atmospheric Peroxy Radicals under Ambient Conditions
}

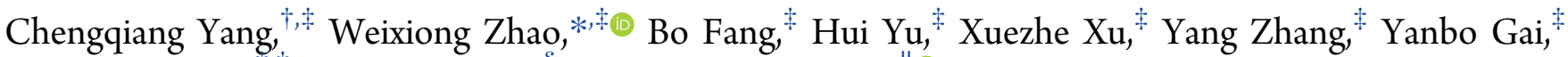 \\ Weijun Zhang, ${ }^{*},+$, Weidong Chen, ${ }^{\S}$ and Christa Fittschen ${ }^{\| \odot}$ \\ ${ }^{\dagger}$ School of Environmental Science and Optoelectronic Technology, University of Science and Technology of China, Hefei 230026, \\ Anhui, China \\ ${ }^{\ddagger}$ Laboratory of Atmospheric Physico-Chemistry, Anhui Institute of Optics and Fine Mechanics, Chinese Academy of Sciences, Hefei \\ 230031, Anhui, China \\ ${ }^{\S}$ Laboratoire de Physicochimie de l'Atmosphère, Université du Littoral Côte d'Opale, 59140 Dunkerque, France \\ "Université Lille, CNRS, UMR 8522-PC2A-Physicochimie des Processus de Combustion et de l'Atmosphère, F-59000 Lille, France
}

Supporting Information

ABSTRACT: In our previous work (Yang et al. Anal. Chem. 2018, 90 (5), 3307-3312), we reported that a large diameter Nafion dryer can be used in the PERCA (PEroxy Radical Chemical Amplification) technique to minimize the impact of water vapor on the chain length (CL). By using a Nafion dryer, the sample was first dried to a low relative humidity $(\mathrm{RH})$ and was then drawn into a FEP (fluorinated ethylene propylene) flow reactor tube to start the amplification cycles for peroxy radical measurement. This method provides a promising and simple method to minimize the sensitivity of CL to water vapor. However, there is a trade-off between inlet radical losses and

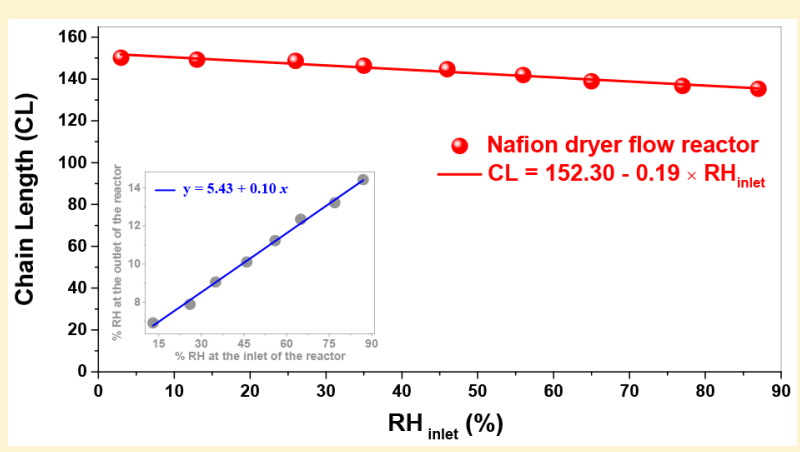
moisture removal efficiency under high ambient $\mathrm{RH}$ conditions. In this paper, we report a further improvement by removing the inlet Nafion dryer and using it directly as an amplifier. The sample was drawn into the Nafion dryer directly without preconditioning to reduce inlet losses; the amplification and $\mathrm{HO}_{2}$ reformation cycles were started in the Nafion dryer. The CL value at $3 \% \mathrm{RH}_{\text {inlet }}$ was about 150 . A linear relationship between $\mathrm{CL}$ and $\mathrm{RH}_{\text {inlet }}$ up to $87 \% \mathrm{RH}$ was observed. Low loss of the $\mathrm{CL}$ under high $\mathrm{RH}_{\text {inlet }}$ (about $10 \%$ reduction at $87 \% \mathrm{RH}$ ) was achieved. As a result, the modified system can largely remove the uncertainty of the CL arising from water vapor under most ambient conditions.

$\mathrm{P}$ eroxy radicals $\left(\mathrm{HO}_{2}\right.$ and $\left.\mathrm{RO}_{2}\right)$ play a significant role in the formation of ozone and secondary organic aerosols and in controlling the atmospheric oxidation capacity. ${ }^{1-3}$ Because of its short lifetime and low concentration, quantifying atmospheric peroxy radicals under ambient conditions present a challenge. ${ }^{4,5}$ Spectroscopic methods provide direct and absolute concentration measurements and can be potentially applied in atmospheric monitoring; ${ }^{6}$ however, limited by the achievable detection sensitivity, the chemical conversion techniques (by measuring other radicals or molecules that peroxy radicals have been converted to, such as laser-induced fluorescence detection of $\mathrm{OH}$, chemical ionization mass spectrometry detection of $\mathrm{H}_{2} \mathrm{SO}_{4}$, and chemical amplified detection of $\mathrm{NO}_{2}$ ) are the current commonly used methods. ${ }^{4,5,7-11}$

The measurement of total peroxy radical $\mathrm{RO}_{2} *\left(\mathrm{RO}_{2} *=\right.$ $\mathrm{HO}_{2}+\Sigma \mathrm{RO}_{2}$ ) by the PERCA (PEroxy Radical Chemical Amplification) technique is achieved by converting $\mathrm{HO}_{2}$ and $\mathrm{RO}_{2}$ to $\mathrm{NO}_{2}{ }^{12}$ by their reaction with $\mathrm{NO}$ and reforming $\mathrm{HO}_{2}$ in a flow reactor in the presence of a chain carrier such as $\mathrm{CO}^{13}$ or ethane $\left(\mathrm{C}_{2} \mathrm{H}_{6}\right),{ }^{14}$ which has been widely used in atmospheric chemistry field studies due to its low-cost and portability. The number of radical reformation cycles before being lost, defined as the chain length (CL), is a critical parameter determining the accuracy and sensitivity of PERCA instruments. ${ }^{15}$ In addition to $\mathrm{CO}$ and $\mathrm{C}_{2} \mathrm{H}_{6}$, model simulations have shown that some organic gases, such as propene $\left(\mathrm{C}_{3} \mathrm{H}_{6}\right)$, ethanol $\left(\mathrm{C}_{2} \mathrm{H}_{5} \mathrm{OH}\right)$, and dimethyl ether $\left(\mathrm{DME}, \mathrm{C}_{2} \mathrm{H}_{6} \mathrm{O}\right)$ can also be used as potential chain carriers. ${ }^{16}$ Owing to the complicated chemistry in the chain propagation reactions and to further reactions of the products of these organic agents, $\mathrm{CO}$ remains the optimum chain carrier selection for PERCA instruments. ${ }^{16}$

Received: October 26, 2018

Accepted: December 17, 2018

Published: December 18, 2018 
For CO-based chemical amplification, the wall loss and water dependent gas phase reactions are the most important chain termination processes that control CL. ${ }^{17-21}$ Compared to dry conditions, the reported CL value is reduced by half at $40 \%$ sample inlet relative humidity $\left(\mathrm{RH}_{\text {inlet }}\right)$ and by a factor of 4 at $70 \% \mathrm{RH}_{\text {inlet. }}{ }^{12,14,18,19,22,23}$ The strong and inconsistent dependence of $\mathrm{CL}$ on sample $\mathrm{RH}$ for different instruments makes accurate correction of water vapor effect a real challenge. ${ }^{17,24}$

To minimize the water sensitivity in our previous work, ${ }^{17}$ we developed a Nafion dryer based dual-channel PERCA instrument. A large diameter Nafion dryer $(18 \mathrm{~mm}$ inner diameter, MD-700, Perma Pure) purged with dry zero air was used to dry the sample to a low $\mathrm{RH}$, and the dried sample was drawn into a FEP (fluorinated ethylene propylene) flow reactor tube to start the amplification cycles for peroxy radical measurements. This method provides a promising and simple method to minimize the impact of water vapor. The Nafion material is a copolymer of Teflon and perfluoro-3,6-dioxa-4methyl-7-octene-sulfonic acid, which can remove water vapor in the sample in milliseconds and does not introduce additional chemical reactions inside the dryer. ${ }^{17,25} \mathrm{~A}$ linear relationship between $\mathrm{CL}$ and $\mathrm{RH}_{\text {inlet }}$ was observed for $\mathrm{RH}_{\text {inlet }}<$ $50 \%$ (about $12 \%$ reduction of $\mathrm{CL}$ at $48 \% \mathrm{RH}_{\text {inlet }}$ compared to $\mathrm{CL}_{\text {dry }}$ at $5 \% \mathrm{RH}_{\text {inlet }}$ ) with a sample flow rate of $5 \mathrm{~L} / \mathrm{min}$ (SLPM, standard liter per minute). As the moisture removal efficiency of the dryer is limited by the inlet flow rate and the length of the dryer, for application in a humid atmosphere $\left(\mathrm{RH}_{\text {inlet }}\right.$ up to ca. $\left.90 \%\right)$, two Nafion dryers in series are needed to maintain the linear relationship of $\mathrm{CL}$ with high $\mathrm{RH}_{\text {inlet }}$. However, doing so doubles the radical inlet wall losses; theoretically, the transmission of $\mathrm{HO}_{2}$ will fall by more than $50 \%$.

This work reports a further improvement on our previous system to expand the usefulness of the PERCA instrument to a wider range of ambient conditions while maintaining low inlet losses and low CL losses at high $\mathrm{RH}_{\text {inlet }}$. Figure 1 shows the schematic of the sample inlet of the improved dual-channel PERCA. The conical prereactor chamber was the same as our previous system, ${ }^{17}$ but the inlet Nafion dryer was removed. Due to low losses at their surface, the Nafion dryers (MD-700, Perma Pure) were used as flow reactors. One dryer operated in amplification mode, and the other one operated in background mode. The sample was drawn into the reactors directly without preconditioning to reduce inlet losses.

The Nafion tube reactor is $70 \mathrm{~cm}$ long with a total volume of about $160 \mathrm{~cm}^{3}$. Since Wood et al. ${ }^{23}$ confirmed that interferences from the thermal decomposition of peroxyacetyl nitrate (PAN) was negligible under most ambient conditions, we set the flow rate to 1.5 SLPM in this paper, giving a residence time of $\sim 6.4 \mathrm{~s}$ in the reactor. Under this condition, the sample can be dried to $14 \% \mathrm{RH}$ at the outlet of the reactor from an inlet RH of $87 \%$ (Supporting Information, Figure S1. The flow rate of the dry purge sheath air was 6 SLPM).

The operation of the instrument is the same as in our previous work. ${ }^{12,17}$ The flow rates of both reagent gases, NO (100 ppmv in $\mathrm{N}_{2}$ ) and CO (99.995\%) were $100 \mathrm{~mL} / \mathrm{min}$. For the Nafion dryer reactor $2, \mathrm{CO}$ was replaced with the same flow rate of $\mathrm{N}_{2}$. At the end of the two reactors, $\mathrm{N}_{2}(100 \mathrm{~mL} /$ $\mathrm{min})$ and $\mathrm{CO}(100 \mathrm{~mL} / \mathrm{min})$ were injected into the sampling line to maintain the same flow conditions in the two reactors and to remove radicals remaining in the reference reactor, respectively. The concentrations of $\mathrm{NO}_{2}$ at each outlet of the

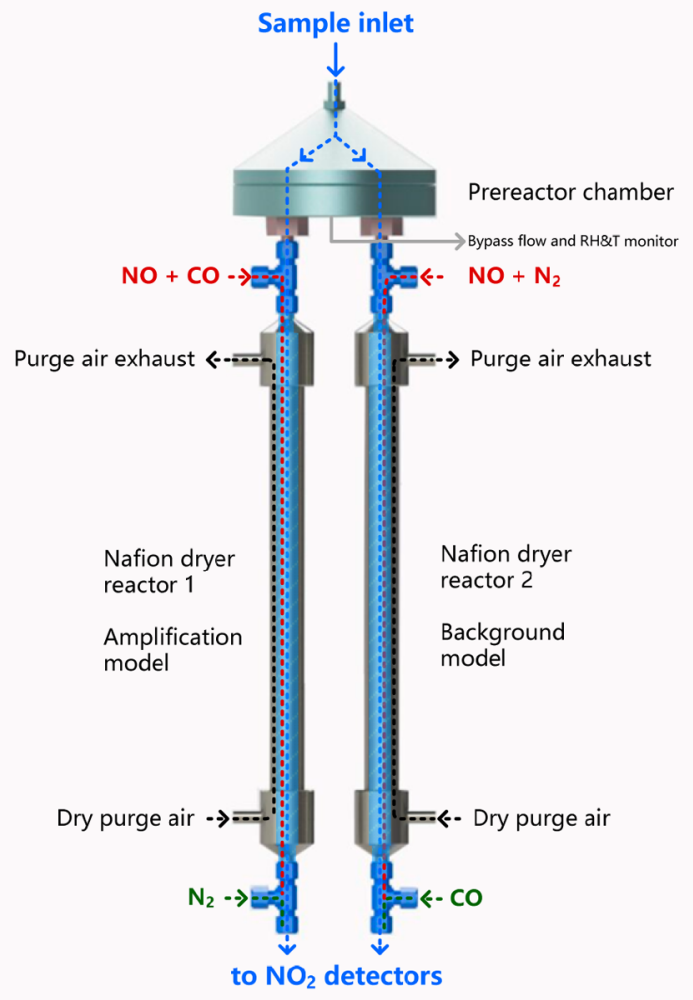

Figure 1. Schematic diagram of the inlet of the improved dualchannel PERCA instrument by using Nafion dryers as the reaction and reference flow reactors.

Nafion dryer reactors were measured with two broadband cavity enhanced spectroscopy (BBCES) detectors. ${ }^{26}$

Several peroxy radical sources can be used for the CL calibration, which include photolysis of $\mathrm{H}_{2} \mathrm{O}$ at $184.9 \mathrm{~nm},{ }^{18,27}$ methyl iodide $\left(\mathrm{CH}_{3} \mathrm{I}\right)^{28}$ and acetone $\left(\mathrm{CH}_{3} \mathrm{C}(\mathrm{O}) \mathrm{CH}_{3}\right)^{23,29}$ at $254 \mathrm{~nm}$, and thermal decomposition of peroxyacetyl nitrate (PAN $)^{15}$ and $\mathrm{H}_{2} \mathrm{O}_{2} \cdot{ }^{30}$ The last source was used in this work. Thermal decomposition of $\mathrm{H}_{2} \mathrm{O}_{2}$ provides a simple, stable, and easily field used $\mathrm{HO}_{2}$ source. Examples of the CL calibration at $3 \%, 56 \%$, and $87 \% \mathrm{RH}_{\text {inlet }}$ were shown in Figure S2 in the Supporting Information. The CL value obtained $(\sim 150)$ was about 1.6 times better than that of our earlier PFA tube reactor (CL 92.5). ${ }^{17}$ The $\mathrm{RH}$ effect on CL of the Nafion dryer reactor is shown in Figure 2a. For comparison, the results of our previous work ${ }^{17}$ with a Nafion dryer inlet and PFA reactors are shown in Figure 2b. With the Nafion dryer reactor, a linear relationship between $\mathrm{CL}$ and $\mathrm{RH}_{\text {inlet }}$ was found up to $87 \% \mathrm{RH}$. Small decreases in the CL under high $\mathrm{RH}_{\text {inlet }}$ (about a $10 \%$ reduction at $87 \% \mathrm{RH}$ ) were achieved. This demonstrates that the system can largely remove the impact of water vapor on $\mathrm{CL}$ and is suited to most ambient conditions.

Nafion dryer removes water by absorbing water with the sulfonic acid group, which is a first-order kinetic reaction and is rapidly proceeded. ${ }^{25}$ The dryer initially removes water faster at the inlet with high differential water vapor pressure inside and outside the tube, then slows down, and finally stops drying after reaching an equilibrium. There is an RH gradient inside the dryer. The model of the gas phase chemistry inside and hence its effect on CL is complex, but obviously this mixed effect can reduce the water sensitivity on CL at each step of the chain propagation reaction. 


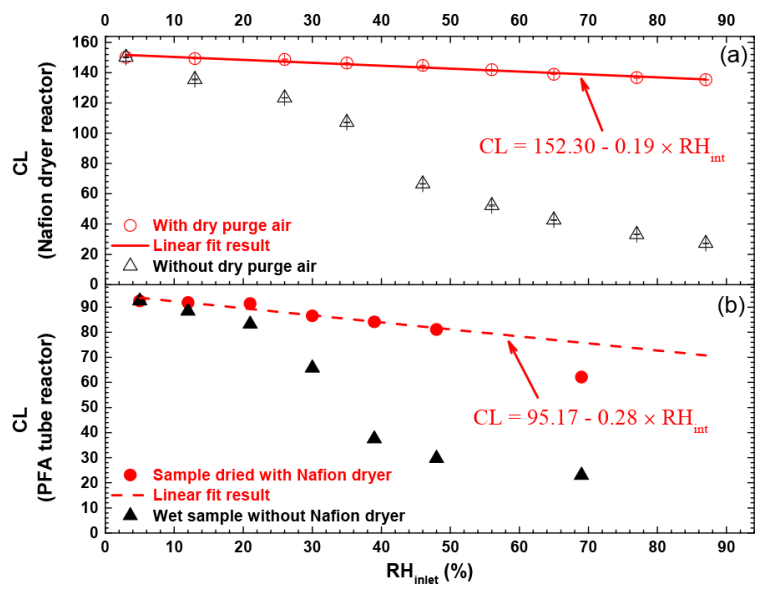

Figure 2. (a) Influence of $\mathrm{RH}_{\text {inlet }}$ on $\mathrm{CL}$ for Nafion dryer amplification reactor with and without dry purge air. The $\mathrm{RH}$ of the sample was controlled with a Perma Pure FC 125-240 series gas humidifier. As humidity above $87 \%$ is difficult to achieve with current humidifier, $\mathrm{RH}_{\text {inlet }}$ larger than this value was not tested. (b) Results from our previous PFA tube reactor with and without Nafion dryer for a comparison. Linear fits of the data are also shown.

The relationship between $\mathrm{CL}$ and $\mathrm{RH}_{\text {inlet }}$ for the Nafion dryer reactor without the dry purge air (open triangles in Figure 2a) and PFA tube with wet sample without drying (filled triangles in Figure 2b) have a similar pattern, suggesting that the chain propagation chemistry inside the Nafion dryer was similar to that in PFA tube reactor. The modest slope of $\mathrm{CL}$ values with $\mathrm{RH}_{\text {inlet }}$ for the sample in the Nafion dryer with the dry purge air (open circles in Figure 2a, with a slope of $-0.19)$ was reasonably similar to that for the dried sample in the PFA tube reactor (filled circles in Figure 2b, with a slope of -0.28). This further demonstrates that humidity was the primary driver in reducing CL. By using Nafion dryer as a reactor, the PERCA system achieved high performance (with higher CL values, 150 to 135 , over a wide sample $\mathrm{RH}, 3 \%$ to $87 \%$, with a linear relationship).

For demonstration purposes of the improved PERCA instrument, ambient $\mathrm{RO}_{2}{ }^{*}$ measurements were made at the Guangzhou Institute of Geochemistry, Chinese Academy of Sciences (GIG, CAS), which is located in the Pearl River Delta (PRD) region in Southern China. ${ }^{17}$ It is an urban environment site surrounded by residential buildings and is next to the Guangyuan Expressway and Huanan Expressway. Measurement results over the period of September 19-26, 2018 are shown in Figure 3. A clear diurnal variation of $\mathrm{RO}_{2} *$ was observed. The maximum $\mathrm{RO}_{2} *$ concentration in this work was about $360 \mathrm{pptv}$, in agreement with previous results (334 pptv at the Guangzhou Back Garden site). ${ }^{5,17}$ The mechanisms for the formation of peroxy radicals are not the part of this work; however, the diel results show clear nocturnal production. ${ }^{31,32}$ Understanding the oxidation chemistry in the daylight as well as in the night time will improve the understanding of the roles of nature and anthropogenic emission precursors in severe ozone pollution, ${ }^{33}$ especially in the PRD region where photochemistry is active. ${ }^{34}$ For most ambient conditions, the $\mathrm{RH}$ of the sample was smaller than $90 \%$. The CL value under ambient $\mathrm{RH}\left(\mathrm{CL}_{\text {wet }}\left(\mathrm{RH}_{\text {ambient }}\right)\right)$ was corrected based on the linear fit result from Figure 2a: $\mathrm{CL}_{\text {wet }}\left(\mathrm{RH}_{\text {ambient }}\right) / \mathrm{CL}_{\mathrm{dry}}(3 \%$ $\mathrm{RH})=1-1.25 \times 10^{-3} \times \mathrm{RH}_{\text {ambient }}$ as shown in Figure 3a. The differences between the $\mathrm{RH}$ corrected $\mathrm{RO}_{2} *$ concentrations with the data calculated with $\mathrm{CL}_{\mathrm{dry}}$ ranged from 3 to $14 \%$.

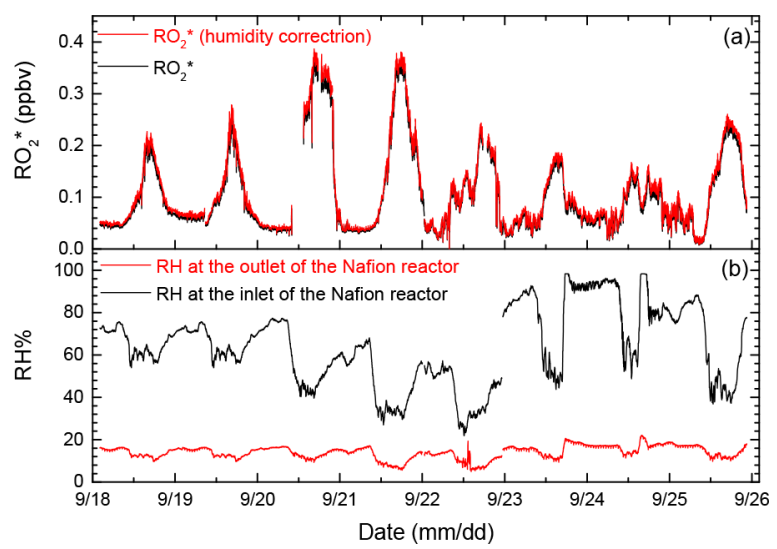

Figure 3. Time series of (a) the peroxy concentrations with (red line) and without (black line) humidity corrections and (b) the measured $\mathrm{RH}$ at the inlet (black line) and the outlet (red lines) of the Nafion dryer reactor. One minute averaged data are shown here.

These relatively modest changes underscore the stable performance of the Nafion dryer reactor.

Here we need to point out that only $\mathrm{HO}_{2}$ calibration was performed in this work. As the $\mathrm{HO}_{2}$ inlet losses are included in the derivation of effective $\mathrm{CL}$, the measurements of ambient $\mathrm{HO}_{2}$ are not affected by using a pure $\mathrm{HO}_{2}$ calibration source $\left(\mathrm{CL}_{\mathrm{HO} 2}\right) .{ }^{11,19,24}$ However, for organic peroxy radicals' measurements, the instrument sensitivities are not the same for all $\mathrm{RO}_{2}$ as it is for $\mathrm{HO}_{2}$, which are dependent on the organic structures of the $\mathrm{R}$ groups. ${ }^{1,30,35} \mathrm{~A}$ list of the theoretical calculated and experimental measured conversion efficiencies of some selected $\mathrm{RO}_{2}$ to $\mathrm{HO}_{2}\left(\mathrm{Y}_{\mathrm{HO} 2}\right.$, determined by the competition reactions to form organic nitrates and nitrites) can be found in refs 11,30 , and 35 . The differences in $\mathrm{Y}_{\mathrm{HO} 2}$ and the inlet wall losses will affect the value of effective $\mathrm{CL}$ compared to $\mathrm{CL}_{\mathrm{HO} 2}$. Higher effective $\mathrm{CL}$ value for $\mathrm{CH}_{3} \mathrm{O}_{2}$ radical was observed in Kartal et al.'s work. ${ }^{19}$ An overestimation $\left(8-16 \%\right.$ depending on the partition of $\mathrm{RO}_{2}$ species) of $\mathrm{RO}_{2}{ }^{*}$ will happen by using $\mathrm{CL}_{\mathrm{HO} 2}$ for analyzing all ambient measurements. ${ }^{19,24}$ This radical partitioning uncertainty in effective CL will always exist in PERCA systems due to the variations in the ratio of $\mathrm{RO}_{2} *$ to $\mathrm{HO}_{2}$, which is related to local $\mathrm{NO}$ and VOC content. However, since $\mathrm{HO}_{2}$ and $\mathrm{CH}_{3} \mathrm{O}_{2}$ radicals are the typically dominant components, the distinction of these two species ${ }^{29,30}$ and the use of CL values from different calibration sources ${ }^{36,37}$ will help in improving the accuracy of the measurement and will make the PERCA instrument better employed in field applications.

In conclusion, we demonstrate (1) that the Nafion dryer reactor can achieve a higher CL than the commonly used PFA tube reactor and (2) that there is a relatively small decrease in $\mathrm{CL}_{\text {wet }}$ over a wide sample $\mathrm{RH}$ (up to $87 \%$ ). The water sensitivity was strongly suppressed in the Nafion dryer reactor and improved the overall PERCA system performance in quantifying $\mathrm{RO}_{2}{ }^{*}$ concentrations with high sensitivity and high accuracy under most (even very humid) ambient conditions. Since the Nafion tube is commercially available and no additional mechanical processing is required, the method shown in this paper can be easily realized. We suggest that this is a simple and attractive approach for research groups to determine peroxy radical chemistry in field and chamber applications. 


\section{ASSOCIATED CONTENT}

\section{S Supporting Information}

The Supporting Information is available free of charge on the ACS Publications website at DOI: 10.1021/acs.analchem.8b04907.

Moisture removal performance of the MD-700 Nafion drier with 1.5 SLPM flow rate and the example calibration of the CLs at $3 \%, 56 \%$, and $87 \% \mathrm{RH}_{\text {inlet }}$ (PDF)

\section{AUTHOR INFORMATION}

\section{Corresponding Authors}

*Phone: +86-551-65591961. Fax: +86-551-65591560. E-mail: wxzhao@aiofm.ac.cn.

*E-mail: wjzhang@aiofm.ac.cn.

\section{ORCID}

Weixiong Zhao: 0000-0003-1700-8992

Christa Fittschen: 0000-0003-0932-432X

Notes

The authors declare no competing financial interest.

\section{ACKNOWLEDGMENTS}

The authors wish to thank Dr. Wei Song at GIG, CAS for her support during the field measurements and Dr. Dean Venables, University College Cork, for assistance with the manuscript. This research is supported by the National Key Research and Development Program of China (Grant 2016YFC0202205), the National Natural Science Foundation of China (Grants 41375127, 91544228), the Natural Science Foundation of Anhui Province (Grant 1508085J03), the Youth Innovation Promotion Association CAS (Grant 2016383), and the CAS President's International Fellowship Initiative (PIFI) Project.

\section{REFERENCES}

(1) Monks, P. S. Chem. Soc. Rev. 2005, 34, 376-395.

(2) Orlando, J. J.; Tyndall, G. S. Chem. Soc. Rev. 2012, 41, 62946317

(3) Lu, K.; Guo, S.; Tan, Z.; Wang, H.; Shang, D.; Liu, Y.; Li, X.; Wu, Z.; Hu, M.; Zhang, Y. Natl. Sci. Rev. 2018, DOI: 10.1093/nsr/ nwy073.

(4) Cantrell, C. A.; Shetter, R. E.; McDaniel, A. H.; Calvert, J. G. In Measurement Challenges in Atmospheric Chemistry; Advances in Chemistry; American Chemical Society: Washington, DC, 1993; pp 291-322.

(5) Li, X.; Lu, K.; Wei, Y.; Tang, X. Prog. Chem. 2014, 26, 682-694.

(6) Onel, L.; Brennan, A.; Gianella, M.; Ronnie, G.; Lawry Aguila, A.; Hancock, G.; Whalley, L.; Seakins, P. W.; Ritchie, G. A. D.; Heard, D. E. Atmos. Meas. Tech. 2017, 10, 4877-4894.

(7) Fuchs, H.; Holland, F.; Hofzumahaus, A. Rev. Sci. Instrum. 2008, 79, No. 084104.

(8) Onel, L.; Brennan, A.; Seakins, P. W.; Whalley, L.; Heard, D. E. Atmos. Meas. Tech. 2017, 10, 3985-4000.

(9) Reiner, T.; Hanke, M.; Arnold, F. J. Geophys. Res. 1997, 102, $1311-1326$

(10) Sadanaga, Y.; Matsumoto, J.; Sakurai, K.; Isozaki, R.; Kato, S.; Nomaguchi, R.; Bandow, H.; Kajii, Y. Rev. Sci. Instrum. 2004, 75, 864-872.

(11) Brookes, D. Characterisation of a PeRCA instrument and measurements of peroxy radicals during the West African Monsoon 2006. Ph.D. Thesis, University of Leicester, Leicester, U.K., November 2009.

(12) Chen, Y.; Yang, C.; Zhao, W.; Fang, B.; Xu, X.; Gai, Y.; Lin, X.; Chen, W.; Zhang, W. Analyst 2016, 141, 5870-5878.
(13) Cantrell, C. A.; Stedman, D. H. Geophys. Res. Lett. 1982, 9, 846-849.

(14) Wood, E. C.; Deming, B. L.; Kundu, S. Environ. Sci. Technol. Lett. 2017, 4, 15-19.

(15) Hastie, D. R.; Weissenmayer, M.; Burrows, J. P.; Harris, G. W. Anal. Chem. 1991, 63, 2048-2057.

(16) Anastasi, C.; Gladstone, R. V.; Sanderson, M. G. Environ. Sci. Technol. 1993, 27, 474-482.

(17) Yang, C.; Zhao, W.; Fang, B.; Xu, X.; Zhang, Y.; Gai, Y.; Zhang, W.; Venables, D. S.; Chen, W. Anal. Chem. 2018, 90, 3307-3312.

(18) Reichert, L.; Hernandez, M. D. A.; Stobener, D.; Burkert, J.; Burrows, J. P. J. Geophys. Res. 2003, 108, 4017.

(19) Kartal, D.; Andrés-Hernández, M. D.; Reichert, L.; Schlager, H.; Burrows, J. P. Atmos. Chem. Phys. 2010, 10, 3047-3062.

(20) Mihele, C. M.; Hastie, D. R. Geophys. Res. Lett. 1998, 25, 1911-1913.

(21) Mihele, C. M.; Mozurkewich, M.; Hastie, D. R. Int. J. Chem. Kinet. 1999, 31, 145-152.

(22) Liu, Y.; Zhang, J. Anal. Chem. 2014, 86, 5391-5398.

(23) Wood, E. C.; Charest, J. R. Anal. Chem. 2014, 86, 1026610273

(24) Andrés-Hernández, M. D.; Stone, D.; Brookes, D. M.; Commane, R.; Reeves, C. E.; Huntrieser, H.; Heard, D. E.; Monks, P. S.; Burrows, J. P.; Schlager, H.; Kartal, D.; Evans, M. J.; Floquet, C. F. A.; Ingham, T.; Methven, J.; Parker, A. E. Atmos. Chem. Phys. 2010, 10, 10621-10638.

(25) Perma Pure Home Page. http://www.permapure.com (accessed October 20, 2018).

(26) Fang, B.; Zhao, W.; Xu, X.; Zhou, J.; Ma, X.; Wang, S.; Zhang, W.; Venables, D. S.; Chen, W. Opt. Express 2017, 25, 26910-26922.

(27) Schultz, M.; Heitlinger, M.; Mihelcic, D.; Volz-Thomas, A. J. Geophys. Res. 1995, 100, 18811-19916.

(28) Clemitshaw, K. C.; Carpenter, L. J.; Penkett, S. A.; Jenkin, M. E. J. Geophys. Res. 1997, 102, 25405-25416.

(29) Miyazaki, K.; Parker, A. E.; Fittschen, C.; Monks, P. S.; Kajii, Y. Atmos. Meas. Tech. 2010, 3, 1547-1554.

(30) Cantrell, C. A.; Shetter, R. E.; Lind, J. A.; McDaniel, A. H.; Calvert, J. G.; Parrish, D. D.; Fehsenfeld, F. C.; Buhr, M. P.; Trainer, M. J. Geophys. Res. 1993, 98, 2897-2909.

(31) Monks, P. S.; Carpenter, L. J.; Penkett, S. A.; Ayers, G. P. Geophys. Res. Lett. 1996, 23, 535-538.

(32) Andrés-Hernández, M. D.; Kartal, D.; Crowley, J. N.; Sinha, V.; Regelin, E.; Martínez-Harder, M.; Nenakhov, V.; Williams, J.; Harder, H.; Bozem, H.; Song, W.; Thieser, J.; Tang, M. J.; Hosaynali Beigi, Z.; Burrows, J. P. Atmos. Chem. Phys. 2013, 13, 5731-5749.

(33) Anderson, D. C.; Pavelec, J.; Daube, C.; Herndon, S. C.; Knighton, W. B.; Lerner, B. M.; Roscioli, J. R.; Yacovitch, T. I.; Wood, E. C. Atmos. Chem. Phys. Discuss. 2018, 1.

(34) Hofzumahaus, A.; Rohrer, F.; Lu, K.; Bohn, B.; Brauers, T.; Chang, C. C.; Fuchs, H.; Holland, F.; Kita, K.; Kondo, Y.; Li, X.; Lou, S.; Shao, M.; Zeng, L.; Wahner, A.; Zhang, Y. Science 2009, 324, $1702-1704$

(35) Ashbourn, S. F. M.; Jenkin, M. E.; Clemitshaw, K. C. J. Atmos. Chem. 1998, 29, 233-266.

(36) Mihele, C. M.; Hastie, D. R. J. Atmos. Ocean. Technol. 2000, 17, $788-794$.

(37) Qi, B.; Takami, A.; Hatakeyama, S. Anal. Sci. 2006, 22, 10911093. 